\title{
Judo Economics in Markets with Multiple Firms
}

\author{
Daniel Cracau ${ }^{1}$ and Benjamin Franz ${ }^{2}$ \\ ${ }^{1}$ Faculty of Economics and Management, University of Magdeburg, Universitätsplatz 2, 39106 Magdeburg, Germany \\ ${ }^{2}$ Mathematical Institute, University of Oxford, 24-29 St Giles', Oxford OX1 3LB, UK
}

Correspondence should be addressed to Daniel Cracau; daniel.cracau@gmail.com

Received 5 May 2014; Revised 22 July 2014; Accepted 9 October 2014; Published 13 November 2014

Academic Editor: Domenico Vitulano

Copyright (C) 2014 D. Cracau and B. Franz. This is an open access article distributed under the Creative Commons Attribution License, which permits unrestricted use, distribution, and reproduction in any medium, provided the original work is properly cited.

\begin{abstract}
We study a sequential Bertrand game with one dominant market incumbent and multiple small entrants selling homogeneous products. Whilst the equilibrium for the case of a single entrant is well known from Gelman and Salop (1983), we derive properties of the $N$-firm equilibrium and present an algorithm that can be used to calculate this equilibrium. The algorithm is based on a recursive manipulation of polynomials that derive the optimisation problem that each of the market entrants is facing. Using this algorithm we derive the exact equilibrium for the cases of two and three small entrants. For more than three entrants only approximate results are possible. We use numerical results to gain further understanding of the equilibrium for an increasing number of firms and in particular for the case where $N$ diverges to infinity. Similarly to the two-firm Judo equilibrium, we see that a capacity limitation for the small firms is necessary to achieve positive profits.
\end{abstract}

\section{Introduction}

Gelman and Salop [1] show that, in a sequential Bertrand competition between one entrant and a single market incumbent selling nondifferentiated products, capacity limitation is necessary for the entrant to be accommodated. For the market incumbent, it is beneficial to serve the residual market at a high (residual) monopoly price rather than cutting down the price for all customers. Because the small entrant uses the incumbent's large size to its own advantage-it is somewhat bound to serve its large customer base at a single price-this entry strategy is called Judo economics [1].

This theoretical result has been confirmed by various studies found in the economic literature. Thomas [2] finds empirical evidence for successful Judo-type entrants in various branches. Using a controlled laboratory experiment, Cracau and Sadrieh [3] show that Judo limitation is a powerful tool for entrants in different market environments including multiple incumbents and a cost advantage for the entrant. Theoretical work has elaborated the original setting and introduced dynamics [4], an altered sequence of capacity and pricing decisions [5], or asymmetric firms [6].

In this paper, we study the extension of Judo limitation of a single entrant to a market situation with multiple entrants.
Such a Judo-type setting with a market incumbent and multiple capacity-limited competitors can, for example, account for the competition among airlines on certain flight routes. We start by reviewing the basic game of Gelman and Salop [1] with a single entrant, before we present some properties of the general $\mathrm{N}$-firm equilibrium. We hope to contribute to the existing literature of extensions of duopoly markets to oligopolies. In particular, we compare our outcomes to a number of extensions for the sequential game of von Stackelberg [7], for example, presented in Boyer and Moreaux [8], Robson [9], and Anderson and Engers [10].

\section{Model Preliminaries}

We study $N$ firms in a sequential Bertrand competition with firms $i=1, \ldots, N-1$ being the first moving entrants and firm $i=N$ being the last moving market incumbent.

Assumption 1. Market entrants move in lexicographic order, with firm $i+1$ making its choice after firm $i$.

Without this assumption, that is, with a simultaneous price competition between multiple small entrants, 
the Bertrand outcome would emerge and no small entrant could achieve a positive profit.

Assumption 2. Products are homogeneous. Consumers' valuation of products is $W>0$.

Assumption 3. Total market demand $D>0$ is fixed.

In the first phase of the game, the market entrants $i=$ $1, \ldots, N-1$ decide one after another on their prices $0<$ $p_{i} \leq W$ and a capacity $0<k_{i} \leq D$. In the second phase, the incumbent decides on its price $0<p_{N} \leq W$ and its output is adjusted according to the (residual) demand at its chosen price. This is equivalent to assuming that the incumbent has no capacity limitation, due to its dominant position in the considered market.

Assumption 4. Consumers' preferences are lexicographic; that is, consumers buy from the firm with the lowest price. In case of equal prices, later moving firms are preferred.

Under Assumptions 2-4 and efficient rationing, firms' sales $s_{i}$ depend on the decisions of all firms as well as on the market parameters.

Assumption 5. Firms face symmetric cost

$$
\kappa\left(s_{i}\right)=C s_{i}+F
$$

where $0 \leq C<W$ denotes constant marginal production costs and $F \geq 0$ denotes fixed market entry costs.

The assumed variable part of the cost only relates to realized production. In particular, we assume no cost associated with the entrants' or incumbent's choice of production capacity.

Firms maximise their total profit $\pi_{i}=p_{i} s_{i}-\kappa\left(s_{i}\right)=$ $\left(p_{i}-C\right) s_{i}-F$. We restrict our analysis to subgame perfect equilibria; that is, if an entrant decides to enter, he will play the subgame perfect price-capacity pair (depending on the number of other entrants). This implies that competitors only enter if they achieve a nonnegative profit $\pi_{i} \geq 0$.

\section{The Basic Judo Equilibrium with Two Firms}

Let us first consider the case $N=2$, that is, a market environment with one small entrant and one dominant market incumbent. As we use a fixed market demand $D$, this setting is a special case of the general 2-firm Judo setting discussed in Gelman and Salop [1].

It is easy to see that any plausible decision of the small entrant (Firm 1) will include a capacity limitation, that is, $k_{1}<D$. In the case $k_{1}=D$, the incumbent firm will always match the small entrant's price $\left(p_{2}=p_{1}\right)$ because it would be left with zero profits if it chooses a higher price $\left(p_{2}>p_{1}\right)$. Due to Assumption 4, the incumbent matching the entrant's price would leave the entrant with zero profits. The small entrant can therefore never obtain positive profits without a capacity limitation. If capacity is limited, the small firm chooses a price-capacity pair in a way that ensures that the dominant incumbent is better off accommodating entry by serving the residual demand at a high price rather than deterring the small firm's entry by matching its price.

Theorem 6. Under Assumptions 1-5, the equilibrium price and capacity choices with one entrant and one incumbent satisfy

$$
p_{1}=\frac{W+C}{2}, \quad k_{1}=\frac{D}{2}, \quad p_{2}=W
$$

Proof. Knowing the small entrant's price $p_{1}$ and capacity $k_{1}$, the dominant firm may either match the small firm's price $\left(p_{2}=p_{1}\right)$ or accommodate $\left(p_{2}>p_{1}\right)$. In the first case, the dominant firm serves the entire market at the price $p_{1}$ and has a profit of

$$
\pi_{2}^{\text {match }}=\left(p_{1}-C\right) D-F
$$

In the second case, the dominant firm serves only the residual demand and therefore maximises its profit by choosing the maximum price $p_{2}=W$. The corresponding profit is

$$
\pi_{2}^{\mathrm{accom}}=(W-C)\left(D-k_{1}\right)-F
$$

Since the small firm has to ensure that entry is accommodated, it must choose a price-capacity pair $\left(p_{1}, k_{1}\right)$ that satisfies the condition

$$
\pi_{2}^{\text {match }} \leq \pi_{2}^{\text {accom }}
$$

that is, the dominant firm's profit from accommodation is not smaller than its profit from deterrence. Substituting the profits and solving for $k_{1}$, this condition takes the form

$$
k_{1} \leq\left(1-\frac{p_{1}-C}{W-C}\right) D .
$$

Then, the small firm faces an optimisation problem of the form

$$
\begin{gathered}
\pi_{1}\left(p_{1}, k_{1}\right)=\left(p_{1}-C\right) k_{1}-F \longrightarrow \max , \\
\text { w.r.t. } k_{1} \leq\left(1-\frac{p_{1}-C}{W-C}\right) D .
\end{gathered}
$$

Gelman and Salop [1] show that the constraint (6) holds with equality in equilibrium. Using this, one can explicitly solve the optimisation problem to find

$$
p_{1}=\frac{W+C}{2}, \quad k_{1}=\frac{D}{2}, \quad p_{2}=W
$$

The equilibrium profits of the firms are

$$
\begin{aligned}
& \pi_{1}=\frac{(W-C) D}{4}-F \\
& \pi_{2}=\frac{(W-C) D}{2}-F\left(>\pi_{1}\right) .
\end{aligned}
$$


Assuming $F \leq(1 / 4)(W-C) D$, the market outcome therefore is the Judo equilibrium as derived in Gelman and Salop [1]. Neglecting fixed cost, the small entrant earns half the profits of the market incumbent, who earns half the monopoly profits. If the fixed cost exceeds the critical value $F_{\text {crit }}=$ $(1 / 4)(W-C) D$, the small entrant cannot cover its market entry cost and will thus stay out of the market. In this case, the dominant incumbent remains the sole firm in the market earning monopoly profits. In either case, being the (last moving) incumbent firm comes along with a strategic advantage and results in higher profits.

\section{Judo Economics in an $N$-Firm Oligopoly}

Let us now consider the full case with $N$ firms that move sequentially according to the preliminaries presented in Section 2. We aim to derive an equilibrium that guarantees a positive profit for every firm $i=1, \ldots, N$. We begin by stating some observations that directly follow from this assumption of positive profits.

Lemma 7. In an N-firm oligopoly as described in Section 2, the following conditions have to be true for every equilibrium that guarantees positive profit for every firm:

$$
\begin{gathered}
C<p_{i}<W, \quad i=1, \ldots, N-1 \\
p_{N}=W, \\
\sum_{i=1}^{N-1} k_{i}<D .
\end{gathered}
$$

Proof. Because every firm earns a positive profit, no firm can be undercut (or matched) by the market incumbent, as the incumbent does not have a capacity constraint and would satisfy all the (residual) demand at its chosen price. Similarly, no firm (including the incumbent) can set a price higher than $W$, as there is no demand for these prices. Therefore, the price of every firm $i=1, \ldots, N-1$ has to be lower than $W$ and higher than $C$. As explained, we also have $p_{N}>p_{i}$, $i=1, \ldots, N-1$ and therefore the optimal choice for firm $N$ is $p_{N}=W$. Similarly, this implies condition (12), as the market incumbent would not make a positive profit with its price choice if this condition was not satisfied.

Using Lemma 7, we can show a further property of the price choices.

Lemma 8. In an equilibrium with positive profits for the $N$ firm oligopoly described in Section 2, the prices $p_{i}$ of all firms are ordered in a nondecreasing way; that is,

$$
p_{1} \leq p_{2} \leq \cdots \leq p_{N-1}<p_{N}
$$

Proof. This property can be easily shown by induction, with the base case $i=1$ trivially satisfied. Assume therefore that the next moving firm is firm $i(i>1)$ and that all the prices so far picked are optimally chosen and nondecreasingly sorted; that is, $p_{1} \leq p_{2} \leq \cdots \leq p_{i-1}<W$. Firm $i$ now calculates its optimal price and capacity choice $\left(p_{i}, k_{i}\right)$. The choice of a price $p_{i}<p_{i-1}$ cannot be optimal in this setting, as choosing $p_{i}=p_{i-1}<W$ would always result in a higher profit, as we know from Lemma 7 that in equilibrium no firm is undercut by the incumbent and therefore each firm always sells its full capacity. Therefore, we have $p_{i} \geq p_{i-1}$ and by induction the argument holds for all $i=2, \ldots, N$. For $p_{N}$ we can additionally rule out equality as was shown in Lemma 7.

Using Lemma 8, we can now derive the exact form of the equilibrium using backwards recursion.

Theorem 9. In equilibrium, the capacity choice of firm $i$ satisfies

$$
k_{i}=P_{i}\left(p_{i}\right)\left(D-\sum_{j=1}^{i-1} k_{j}\right)
$$

where $P_{i}: \mathbb{R} \mapsto \mathbb{R}$ is a polynomial of degree $N-i$. Its optimal price choice is given through

$$
p_{i}^{*}=\underset{p<p_{i+1}^{*}}{\operatorname{argmax}}(p-C) P_{i}(p) .
$$

Proof. We will show this theorem by induction. Let us therefore begin by studying the two possible options of firm $N$. Matching its predecessor's price yields

$$
\pi_{N}^{\mathrm{mat}}=\left(p_{N-1}-C\right)\left(D-\sum_{j=1}^{N-2} k_{j}\right)
$$

whereas choosing to serve residual demand yields

$$
\pi_{N}^{\mathrm{res}}=(W-C)\left(D-\sum_{j=1}^{N-1} k_{j}\right) .
$$

Equilibrium firm $N-1$ has to ensure that both options yield the same profit [1]:

$$
\left(p_{N-1}-C\right)\left(D-\sum_{j=1}^{N-2} k_{j}\right)=(W-C)\left(D-\sum_{j=1}^{N-1} k_{j}\right)
$$

Hence,

$$
\begin{aligned}
k_{N-1} & =\frac{W-C-p_{N-1}+C}{W-C}\left(D-\sum_{j=1}^{N-2} k_{j}\right) \\
& =\left(1-\frac{p_{N-1}-C}{W-C}\right)\left(D-\sum_{j=1}^{N-2} k_{j}\right) \\
& =P_{N-1}\left(p_{N-1}\right)\left(D-\sum_{j=1}^{N-2} k_{j}\right) .
\end{aligned}
$$

We will now consider the equilibrium choices of a general firm $1<i<N$. Let us assume that the price and quantity choice of firm $i$ has to satisfy

$$
k_{i}=P_{i}\left(p_{i}\right)\left(D-\sum_{j=1}^{i-1} k_{j}\right)
$$


(S1) Initialise the polynomial $P_{N}(p)=1$ and $p_{N}^{*}=W$. Set $i=N$.

(S2) Recursively calculate the polynomials

(S3) Calculate $p_{i-1}^{*}$ using

$$
P_{i-1}(p)=1-\frac{(p-C) P_{i}(p)}{\left(p_{i}^{*}-C\right) P_{i}\left(p_{i}^{*}\right)}
$$

$$
p_{i-1}^{*}=\underset{p<p_{i}^{*}}{\arg \max }(p-C) P_{i-1}(p) .
$$

Set $i=i-1$. If $i>1$ continue with (S2).

(S4) Initialise the capacity $k_{1}=P_{1}\left(p_{1}^{*}\right) D$. Set $i=2$.

(S5) Recursively calculate the capacities

$$
k_{i}=P_{i}\left(p_{i}^{*}\right)\left(D-\sum_{j=i}^{i-1} k_{j}\right) .
$$

Set $i=i+1$. If $i<N$ continue with (S5).

(S6) Calculate the equilibrium profits of firms $i=1, \ldots, N-1$ using $\pi_{i}=\left(p_{i}^{*}-C\right) k_{i}$ and of the market incumbent using

$$
\pi_{N}=(W-C)\left(D-\sum_{j=i}^{N-1} k_{j}\right) \text {. }
$$

Algorithm 1: Algorithm to calculate the Judo equilibrium for $N$ firms.

where $P_{i}$ is a polynomial of degree $N-i$ and that its optimal price choice is $p_{i+1}^{*}$. Then firm $i$ has again two possible options: it can match the price of firm $i-1$ and gain the profit

$$
\pi_{i}^{\text {match }}=\left(p_{i-1}-C\right) P_{i}\left(p_{i-1}\right)\left(D-\sum_{j=1}^{i-2} k_{j}\right) .
$$

Alternatively it can choose to accommodate firm $i-1$ by choosing a price higher than $p_{i-1}$. It then faces the optimisation problem

$$
\pi_{i}^{\mathrm{accom}}=\max _{p<p_{i+1}^{*}}(p-C) P_{i}(p)\left(D-\sum_{j=1}^{i-1} k_{j}\right) .
$$

Let us call the optimizer of optimisation problem (22) $p_{i}^{*}$. As the capacities $k_{j}$ are multiplicative in this optimisation problem, they do not influence the position of the maximum. Hence, $p_{i}^{*}$ is independent of all choices made before player $i$. In equilibrium the two possible options of firm $i$ need to yield the same profit:

$$
\begin{aligned}
\left(p_{i-1}-C\right) P_{i}\left(p_{i-1}\right)\left(D-\sum_{j=1}^{i-2} k_{j}\right) \\
=\left(p_{i}^{*}-C\right) P_{i}\left(p_{i}^{*}\right)\left(D-\sum_{j=1}^{i-1} k_{j}\right) .
\end{aligned}
$$

Hence,

$$
\begin{aligned}
k_{i-1} & =\left(1-\frac{\left(p_{i-1}-C\right) P_{i}\left(p_{i-1}\right)}{\left(p_{i}^{*}-C\right) P_{i}\left(p_{i}^{*}\right)}\right)\left(D-\sum_{j=1}^{i-2} k_{j}\right) \\
& =P_{i-1}\left(p_{i-1}\right)\left(D-\sum_{j=1}^{i-2} k_{j}\right),
\end{aligned}
$$

where we define the polynomial $P_{i-1}$ through

$$
P_{i-1}(p)=1-\frac{(p-C) P_{i}(p)}{\left(p_{i}^{*}-C\right) P_{i}\left(p_{i}^{*}\right)},
$$

and $p_{i}^{*}$ is given by

$$
p_{i}^{*}=\underset{p<p_{i+1}^{*}}{\operatorname{argmax}}(p-C) P_{i}(p) .
$$

Note that the degree of polynomial $P_{i-1}$ is equal to the degree of $P_{i}$ plus one. Using the natural initialization for the $N$ th player

$$
p_{N}^{*}=W, \quad P_{N}(p)=1,
$$

it is easy to see that $P_{i}$ is a polynomial of degree $N-i$.

Therefore, the optimisation problem to determine $p_{i}^{*}$ becomes increasingly difficult as $i$ decreases.

From the proof of Theorem 9, we can device an algorithm to calculate the $N$-firm Judo equilibrium for the game presented in Section 2. This algorithm is presented in Algorithm 1. Note that the backwards recursion used in both the proof of Theorem 9 and the algorithm implies that the polynomials and therefore the price choices when read from the last-moving player are independent of the number of firms $N$ in the market. However, the quantity choices depend strongly on the number of players, as will be discussed in Section 6.

\section{Example: Judo Economics with a Second Small Firm}

In order to demonstrate the algorithm to calculate the $N$-firm Judo equilibrium (S1)-(S6), we study the case $N=3$. Let us therefore initialise the algorithm as in (S1):

$$
P_{3}(p)=1, \quad p_{3}^{*}=W .
$$


TABle 1: Overview of equilibrium prices depending on the number of firms $N$.

\begin{tabular}{|c|c|c|c|c|c|c|}
\hline & $N=1$ & $N=2$ & $N=3$ & $N=4$ & $\cdots$ & $N \rightarrow \infty$ \\
\hline$p_{N}$ & $W$ & $W$ & W & W & $\ldots$ & $W$ \\
\hline$p_{N-1}$ & - & $W+C$ & $\underline{W+C}$ & $\underline{W+C}$ & $\ldots$ & $W+C$ \\
\hline & & 2 & $W^{2}+5 C$ & $W^{2}+5 C$ & & $W^{2}+5 C$ \\
\hline$p_{N-2}$ & - & - & 6 & $\left.(7-\sqrt{33}) \frac{6}{W+(17}+\sqrt{33}\right) C$ & $\cdots$ & $\left.(7-\sqrt{33}) \frac{6}{W+(17}+\sqrt{33}\right) C$ \\
\hline$p_{N-3}$ & - & - & - & 24 & $\cdots$ & 24 \\
\hline$\vdots$ & $\vdots$ & $\vdots$ & $\vdots$ & $\vdots$ & $\ddots$ & $\vdots$ \\
\hline$p_{1}$ & $=p_{N}$ & $=p_{N-1}$ & $=p_{N-2}$ & $=p_{N-3}$ & $\cdots$ & C \\
\hline
\end{tabular}

TAble 2: Overview of equilibrium capacities depending on the number of firms $N$.

\begin{tabular}{|c|c|c|c|c|c|c|}
\hline & $N=1$ & $N=2$ & $N=3$ & $N=4$ & $\cdots$ & $N \rightarrow \infty$ \\
\hline & D & $D$ & $5 D$ & $95+15 \sqrt{33}$ & 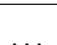 & 0 \\
\hline$\kappa_{N}$ & $D$ & $\begin{array}{l}\overline{2} \\
D\end{array}$ & $\begin{array}{l}\overline{18} \\
5 D\end{array}$ & $\frac{1152}{95+15 \sqrt{33}}$ & $\cdots$ & 0 \\
\hline$k_{N-1}$ & - & 2 & $\begin{array}{l}18 \\
4 D\end{array}$ & $\begin{array}{l}1152 \\
19+3 \sqrt{33}\end{array}$ & $\cdots$ & 0 \\
\hline$k_{N-2}$ & - & - & $\frac{x}{9}$ & $\frac{144}{144 \sqrt{33}} D$ & $\cdots$ & 0 \\
\hline$k_{N-3}$ & - & - & - & $\frac{45-3 \sqrt{35}}{64} D$ & $\cdots$ & 0 \\
\hline$\vdots$ & $\vdots$ & $\vdots$ & $\vdots$ & $\vdots$ & $\ddots$ & $\vdots$ \\
\hline$k_{1}$ & $=k_{N}$ & $=k_{N-1}$ & $=k_{N-2}$ & $=k_{N-3}$ & $\ldots$ & $\approx 0.43$ \\
\hline
\end{tabular}

We can now calculate $P_{2}(p)$ using $(\mathrm{S} 2)$

$$
P_{2}(p)=1-\frac{p-C}{W-C}
$$

The optimisation problem for firm 2 can be formulated according to (S3)

$$
\max _{p<W} p-C-\frac{(p-C)^{2}}{W-C} .
$$

We can easily calculate the maximizer of this optimisation problem to be

$$
p_{2}^{*}=\frac{W+C}{2}
$$

which, as noted before, is the same price choice as that of player 1 in the two player game. We can repeat these steps to calculate $P_{1}(p)$ and $p_{1}^{*}$ :

$$
\begin{gathered}
P_{1}(p)=1-4 \frac{p-C}{W-C}+4\left(\frac{p-C}{W-C}\right)^{2}, \\
p_{1}^{*}=\frac{W+5 C}{6} .
\end{gathered}
$$

Using (S4) and (S5) we can calculate the equilibrium capacities

$$
\begin{aligned}
& k_{1}=P_{1}\left(p_{1}^{*}\right) D=\frac{4 D}{9}, \\
& k_{2}=P_{2}\left(p_{2}^{*}\right)\left(D-k_{1}\right)=\frac{5 D}{18} .
\end{aligned}
$$

Similarly, we can calculate the equilibrium profits using (S6) and derive

$$
\begin{aligned}
& \pi_{1}=\left(p_{1}^{*}-C\right) k_{1}-F=\frac{2(W-C) D}{27}-F, \\
& \pi_{2}=\left(p_{2}^{*}-C\right) k_{2}-F=\frac{5(W-C) D}{36}-F, \\
& \pi_{3}=\left(p_{3}^{*}-C\right)\left(D-k_{1}-k_{2}\right)-F=\frac{5(W-C) D}{18}-F .
\end{aligned}
$$

Note that we have $\pi_{1}<\pi_{2}<\pi_{3}$. In particular, firm 1 now has to choose whether or not to enter the market depending on the entry cost. If the entry costs are below the critical value $F_{\text {crit }}=2(W-C) D / 27$, it will decide to enter the market as it expects a positive profit.

\section{Numerical Analysis of the $N$-Firm Equilibrium}

As discussed in the proof of Theorem 9, the exact solution of the optimisation problem in step (S3) of the algorithm presented in Algorithm 1 gets increasingly difficult. We are able to derive such exact solution only for $N \leq 4$ and present the respective results in Tables 1,2 , and 3. In order to get further insight into the equilibrium for $N>$ 4, we perform a numerical approximation of algorithm (S1)-(S6). The code used to find the approximations presented in this section can be found in the supplementary material (see Supplementary Material available online at http://dx.doi.org/10.1155/2014/216473). In particular, we are interested in the equilibrium characteristics for a large number of firms and ultimately in the limit as $N$ diverges to 
TABLE 3: Overview of equilibrium profits depending on the number of firms $N(F=0)$.

\begin{tabular}{|c|c|c|c|c|c|c|}
\hline & $N=1$ & $N=2$ & $N=3$ & $N=4$ & $\cdots$ & $N \rightarrow \infty$ \\
\hline$\pi_{N}$ & $(W-C) D$ & $\frac{W-C}{2} D$ & $\frac{5(W-C)}{18} D$ & $\frac{95+15 \sqrt{33}}{1152}(W-C) D$ & $\cdots$ & 0 \\
\hline$\pi_{N-1}$ & - & $\frac{W-C}{4} D$ & $\frac{5(W-C)}{36} D$ & $\frac{95+15 \sqrt{33}}{2304}(W-C) D$ & $\cdots$ & 0 \\
\hline$\pi_{N-2}$ & - & - & $\frac{2(w-C)}{27} D$ & $(7-\sqrt{33})^{864}(15-\sqrt{33})$ & $\cdots$ & 0 \\
\hline$\pi_{N-3}$ & - & - & - & $\frac{(W-C) D}{512}(W$ & $\cdots$ & 0 \\
\hline$\vdots$ & $\vdots$ & $\vdots$ & $\vdots$ & $\vdots$ & $\ddots$ & $\vdots$ \\
\hline$\pi_{1}$ & $=\pi_{N}$ & $=\pi_{N-1}$ & $=\pi_{N-2}$ & $=\pi_{N-3}$ & $\cdots$ & 0 \\
\hline
\end{tabular}

infinity. The results are plotted in Figure 1. Note that all the plotted results represent the simplified case where $C=0$, $W=D=1$. These can, however, be rescaled for any value of these parameters, using

$$
\begin{gathered}
p=\widehat{p}(W-C)+C, \quad k=\widehat{k} D, \\
\pi=\widehat{\pi}(W-C) D,
\end{gathered}
$$

where the hats denote variables for $C=0, W=D=1$ presented in Figure 1.

In Figure 1(a), we analyse the capacities chosen by the first moving firm. We can see that this number converges quickly to a value close to 0.43 . This means that the remaining capacity is shared between an increasing number of firms and the result can be seen in Figure 1(b), where we present the remaining quantity for the market incumbent. We see that this quantity decreases exponentially to 0 as the number of small firms increases. This falling quantity combined with the constant price for the market incumbent results in a falling profit, presented in Figure 1(d). Here, we also see the profits of the $(N-1)$ th and $(N-2)$ th firm. As expected, these also decrease exponentially to zero and a constant factor lies below the profit of the market incumbent. The prices chosen by the first entrant are shown in Figure 1(c). Again, this price falls exponentially to 0 and results in a decreasing profit for firm 1. Using this data along with the convergence of $k_{1}$, one can estimate the profit of the first moving firm, which can be interpreted as the critical value of fixed entry costs, above which this firm would not enter the market. One can now approximately construct a function $n(F)$ that indicates the number of firms to be expected in a market with fixed market entry cost $F$.

\section{Discussion}

We have shown that the Judo limitation in capacities is an entry strategy not only for a single entrant competing with a dominant market incumbent but also for the case of multiple small entrants. We presented an equilibrium solution concept and discussed some equilibrium properties for the general case of $N$ firms. For $N \leq 4$ firms, the equilibrium prices, capacities, and profits of each firm can be derived analytically. For a higher number of firms $(N>4)$, equilibrium outcomes can only be calculated numerically.
We found, that for each firm, equilibrium prices do not depend on the total number of firms but only on the position of the entrant. This compares to Boyer and Moreaux [8], who study a Stackelberg game and show that production of each firm $i$ solely depends on the rank of the firm and not on the number of firms in the market. Julien et al. [11] find a similar result in a multistage Stackelberg game with multiple firms in each stage. Output decisions in each stage only depend on the previous output decisions but do not depend on the number of followers or following periods.

We have shown that entrants in our game deciding earlier set lower prices; that is, prices can be ranked and increase with the rank of a firm within the competition. This is compared to Etro [12], who shows that, with endogenous entry in a Stackelberg competition with prices, the first moving firm (the leader) sets a lower price than the (simultaneous moving) followers. At the same time, entrants deciding early in our game choose higher capacities. Overall, deciding earlier in this game yields lower profits.

We also found that the ratio of firms' profits is fixed. This finding is related to Anderson and Engers [10], who show that in a hierarchical Stackelberg oligopoly each firm earns half its immediate predecessor's profit (for linear demand and linear cost). In particular, this is compared to our incumbent firm earning twice as much profit as the last entrant in our sequential model.

Individual profits and capacities (of the small entrants) decrease with an increasing number of entrants. This is in line with Vives [13] who models a game with multiple stages where one market incumbent decides first on its output and then, subsequently, entrants decide whether to enter the market at fixed market entry cost. He finds that the incumbent's profit is nonincreasing in $N$ while total output is increasing in $N$. At the theoretical limit of $N \rightarrow \infty$ in our model, the first entrant has a price equal to the marginal cost level and all firms earn zero profits (the Appendix). The finding that, with an infinite number of firms, the market price converges towards the competitive level is in line with Boyer and Moreaux [8] and Robson [9], who show the same for a Stackelberg game with $N$ firms and linear cost [8] and Ushaped average cost [9].

We have restricted our analysis to the case of multiple entrants deciding in a sequence (Assumption 1). First, in a price competition model as ours, the existence of multiple 


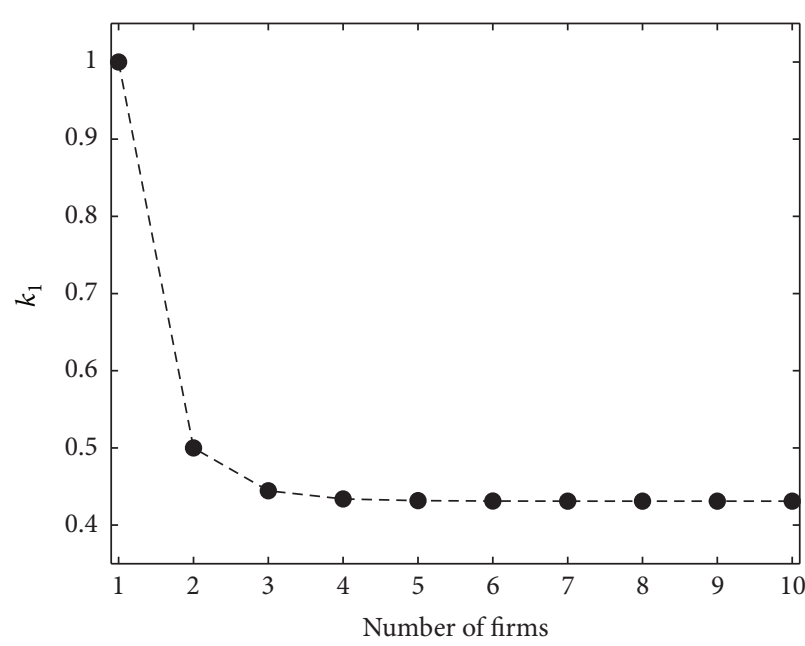

(a) Capacity of last moving entrant

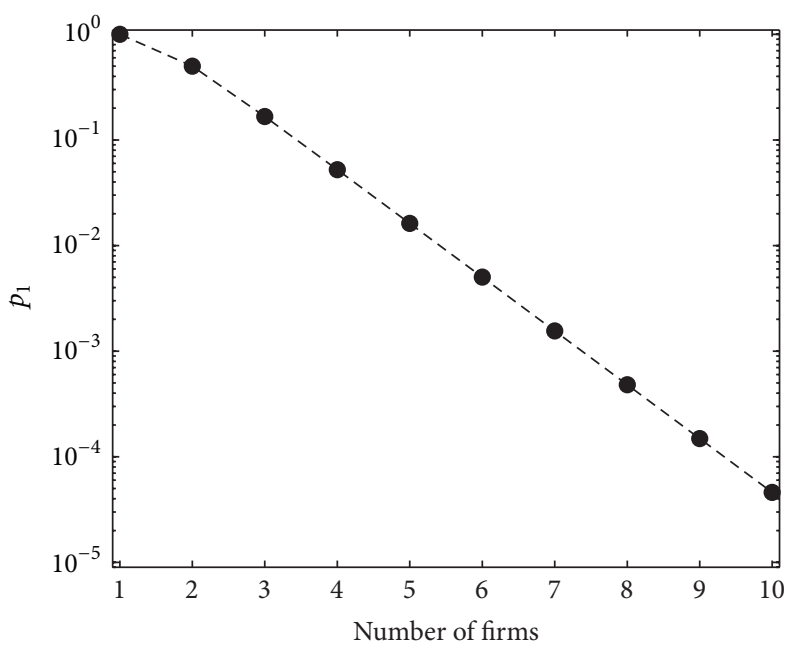

(c) Price of last moving entrant

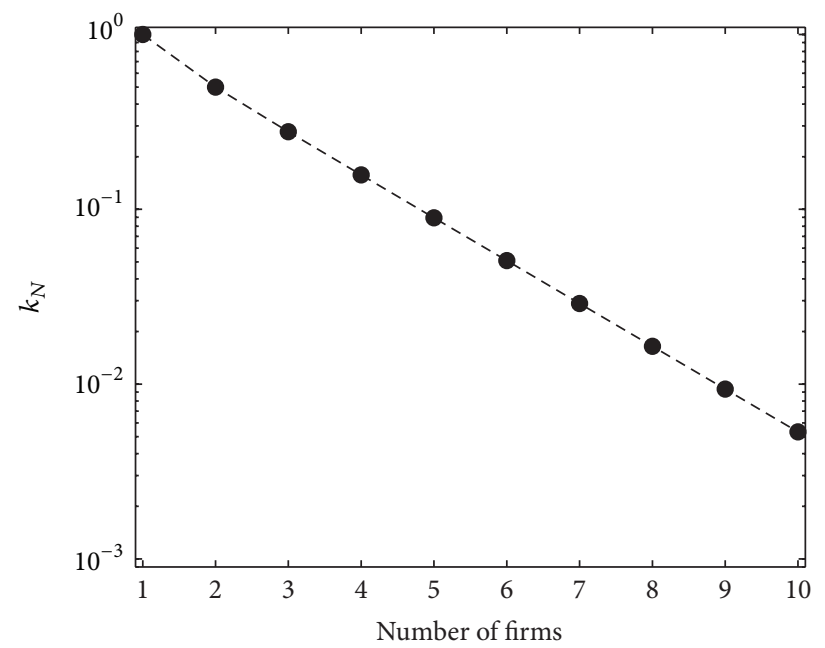

(b) Sales of market incumbent

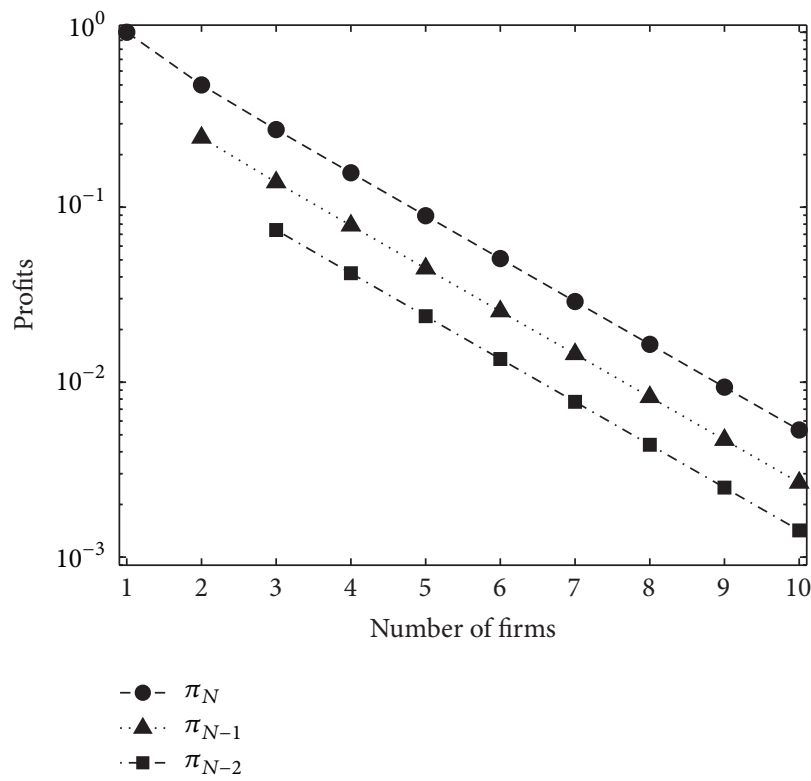

(d) Profits of market incumbent and the two first moving entrants

FIGURE 1: Numerical approximations of the $N$-firm equilibrium presented in Theorem 9.

market incumbents as in Vives [13] is not appropriate for the analysis of sequential entry because the incumbents would play the Bertrand prices at the marginal cost level and thus no room for entrants would be left. Second, we mentioned in Section 2 that simultaneous moves of entrants lead to Bertrand prices at the marginal cost level and no capacity limitation. Thus the market incumbent would always match the price and thereby deter entry. Moreover, the sequence of our game can be justified by different arguments. According to Eaton and Ware ([14], page 14), "(e)ntry by its very nature is sequential, and rational entry requires analysis of a sequential game [...]." Vives [13] argues that potential entrants either decide at different times on entry or, equivalently, some are quicker than others to respond to entry opportunities. Anderson and Engers [10] argue that it is very unlikely that firms actually decide at exactly the same time. They model a quantity competition where firms can decide whether to reveal their output decisions or not. In this model, nonrevealing would be equivalent to playing the simultaneous Cournot game [15]. Anderson and Engers [10], however, show that revealing and thus playing the Stackelberg game is the subgame perfect equilibrium choice.

Assumption 2 (homogeneous products) is crucial for the derivation of our results. For entrants, capacity limitation is only necessary in the absence of any horizontal product differentiation. Furth and Kovenock [16], for example, have shown that in markets with a sequential price competition and differentiated goods, the first moving firm earns 
positive profits without any capacity limitation. In contrast, Assumptions 3 (fixed market demand) and 5 (constant marginal costs) are not crucial for the derivation of our results. To cover altered market conditions, for example, linear market demand or increasing marginal costs, our solution concept as presented in Algorithm 1 only needs to be adjusted accordingly. However, both assumptions make the analytical outcomes more tractable. For settings with linear demand and more than one entrant, for example, equilibrium prices, capacities, and profits can only be derived numerically. The same holds for asymmetric cost, that is, if the marginal costs are modeled as related to the entrants' capacity choice rather than production for all firms. Assumption 4 (lexicographic preferences) is not crucial, but it makes marginal price cuts obsolete and thus simplifies the equilibrium derivation. Finally, Gelman and Salop [1] show that with efficient rationing the equilibrium structure is similar to that with proportional rationing but the distribution of profits is altered.

\section{Concluding Remarks}

In this paper, we study a game with exogenously given cost structure and product valuation. We provide a concept to calculate the equilibrium price choice and profit for each of the firms in the market. Assuming positive market entry cost and endogenous firm entry, this implicitly yields the number of firms in equilibrium.

In our model, we have considered consumers' product valuation $W$, fixed market demand $D$, and firms' marginal cost $C$ as exogenously given market parameters. Built upon our equilibrium solution concept, it is possible to study endogenous market parameters in the presented Judo framework. From Etro [17], we know that in markets with endogenous entry, the dominant leader can have an incentive to be aggressive. In economic terms, this means that the market leader might invest in cost reduction and/or demand enhancement (e.g., increasing product valuation by increased product quality). The incumbent's investment decisions in a setting like ours thus provide a link for future work. Further, our model approach could be used to study costly capacity choices for entrants (We thank an anonymous referee for pointing this out). From the incumbent's viewpoint, capacity holding might work as a barrier to entry in this case; see also Ware [18].

\section{Appendix}

\section{Overview of Equilibrium Outcomes}

See Tables 1, 2, and 3.

\section{Conflict of Interests}

The authors declare that there is no conflict of interests regarding the publication of this paper.

\section{Acknowledgments}

The second author would like to thank the financial support from the European Research Council under the European Community's Seventh Framework Programme (FP7/20072013)/ERC Grant agreement no. 239870. His work is also partly supported by Award no. KUK-C1-013-04, made by King Abdullah University of Science and Technology (KAUST).

\section{References}

[1] J. R. Gelman and S. C. Salop, "Judo economics: capacity limitation and coupon competition," Bell Journal of Economics, vol. 14, no. 2, pp. 315-325, 1983.

[2] L. A. Thomas, "Incumbent firms' response to entry: price, advertising, and new product introduction," International Journal of Industrial Organization, vol. 17, no. 4, pp. 527-555, 1999.

[3] D. Cracau and A. Sadrieh, "Coexistence of small and dominant firms in bertrand competition: judo economics in the lab," FEMM Working Papers 13001, Faculty of Economics and Management, Otto-von-Guericke University Magdeburg, Magdeburg, Germany, 2013.

[4] L. Sørgard, "Judo economics reconsidered: capacity limitation, entry and collusion," International Journal of Industrial Organization, vol. 15, no. 3, pp. 349-368, 1997.

[5] B. Allen, R. Deneckere, T. Faith, and D. Kovenock, "Capacity precommitment as a barrier to entry: a bertrand-edgeworth approach," Economic Theory, vol. 15, no. 3, pp. 501-530, 2000.

[6] D. Cracau, "Judo economics in markets with asymmetric firms," Economics Letters, vol. 119, no. 1, pp. 35-37, 2013.

[7] H. von Stackelberg, Marktform und Gleichgewicht, Springer, Berlin, Germany, 1934.

[8] M. Boyer and M. Moreaux, "Perfect competition as the limit of a hierarchical market game," Economics Letters, vol. 22, no. 2-3, pp. 115-118, 1986.

[9] A. J. Robson, "Stackelberg and marshall," The American Economic Review, vol. 80, no. 1, pp. 69-82, 1990.

[10] S. P. Anderson and M. Engers, "Stackelberg versus cournot oligopoly equilibrium," International Journal of Industrial Organization, vol. 10, no. 1, pp. 127-135, 1992.

[11] L. A. Julien, O. Musy, and A. W. Saïdi, "On hierarchical competition in oligopoly," Journal of Economics, vol. 107, no. 3, pp. 217-237, 2012.

[12] F. Etro, "Stackelberg competition with endogenous entry," Economic Journal, vol. 118, no. 532, pp. 1670-1697, 2008.

[13] X. Vives, "Sequential entry, industry structure and welfare," European Economic Review, vol. 32, no. 8, pp. 1671-1687, 1988.

[14] B. C. Eaton and R. Ware, "A theory of $m$ arket structure with sequential entry," RAND Journal of Economics, vol. 18, no. 1, pp. $1-16,1987$.

[15] A. A. Cournot, Recherches sur les Principes Mathematiques de la Theorie des Richesses, translated by N. Bacon, Macmillan, New York, NY, USA, 1927, Hachette, Paris, France, 1838.

[16] D. Furth and D. Kovenock, "Price leadership in a duopoly with capacity constraints and product differentiation," Journal of Economics, vol. 57, no. 1, pp. 1-35, 1993.

[17] F. Etro, "Aggressive leaders," RAND Journal of Economics, vol. 37, no. 1, pp. 146-154, 2006.

[18] R. Ware, "Inventory holding as a strategic weapon to deter entry," Economica, vol. 52, no. 205, pp. 93-101, 1985. 


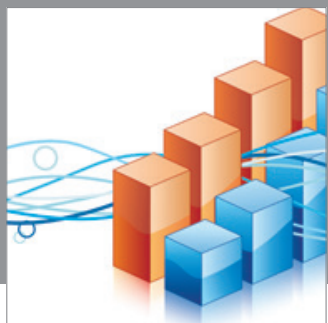

Advances in

Operations Research

mansans

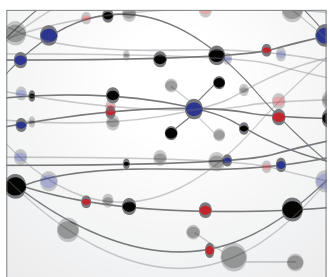

The Scientific World Journal
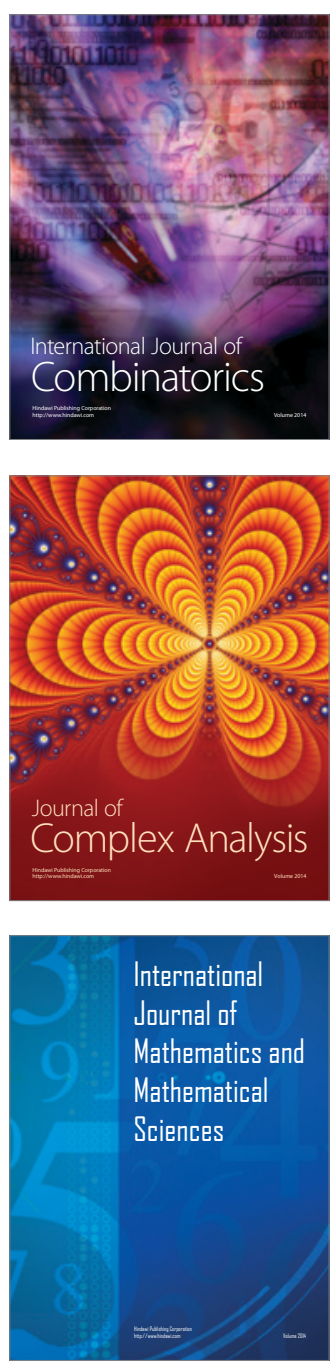
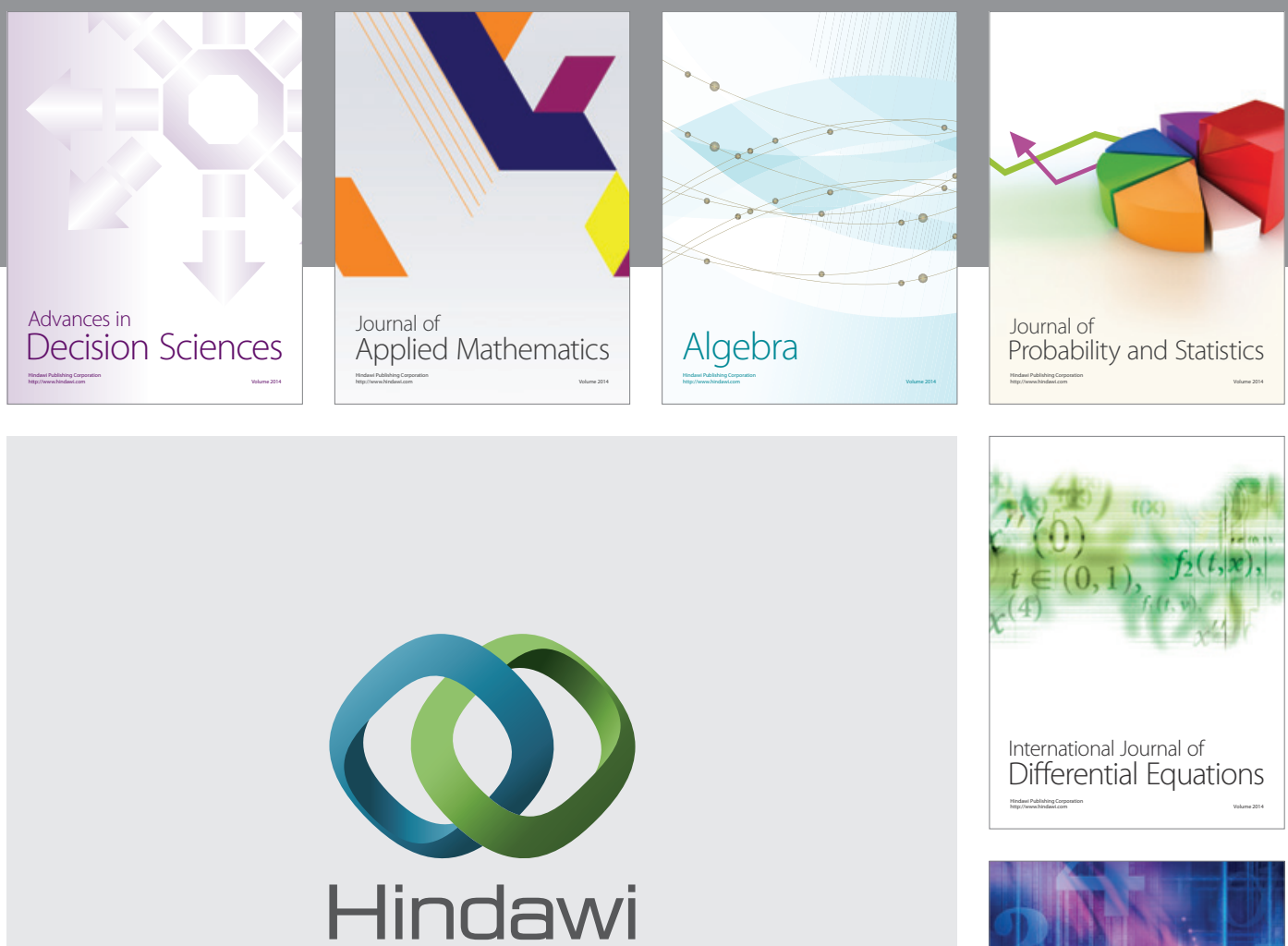

Submit your manuscripts at http://www.hindawi.com
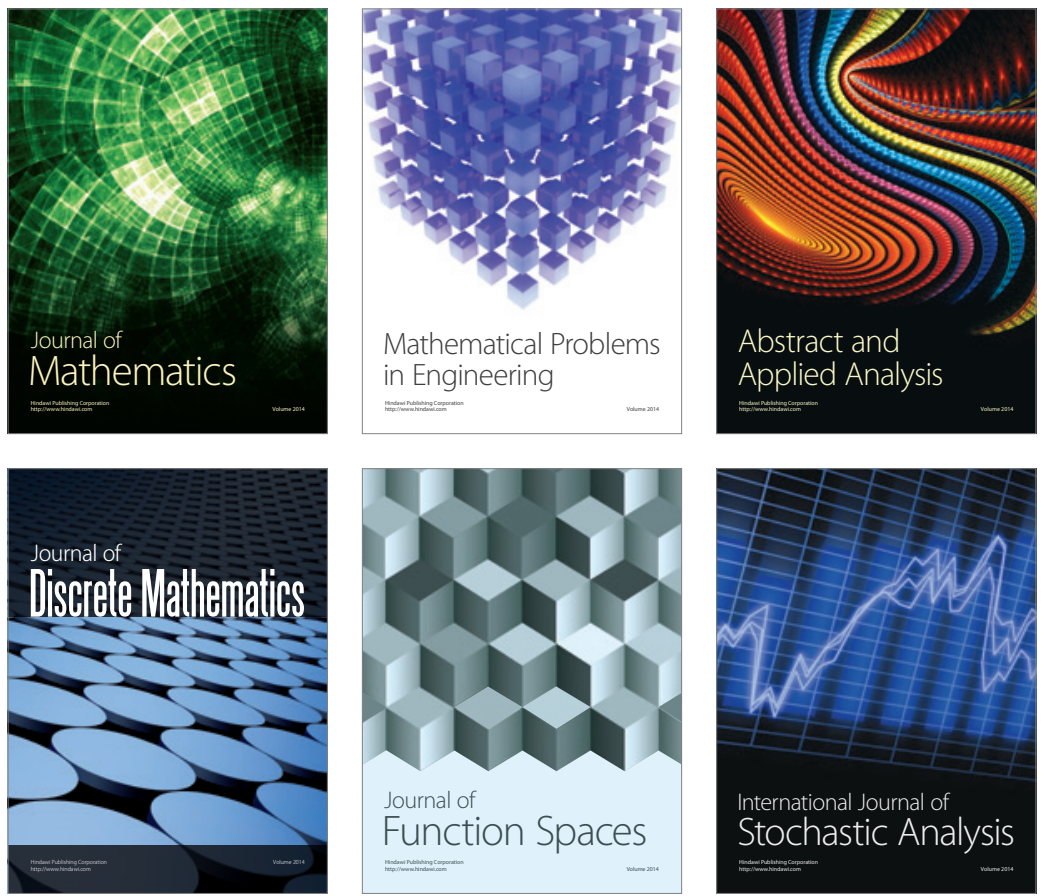

Journal of

Function Spaces

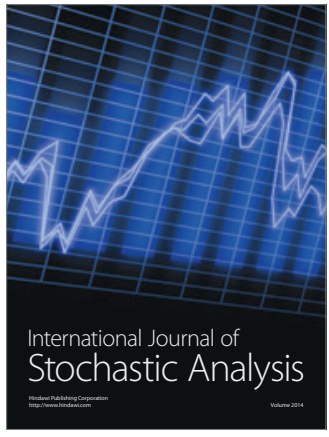

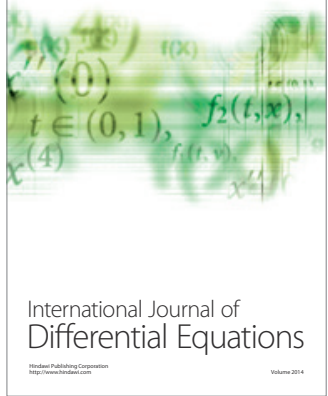
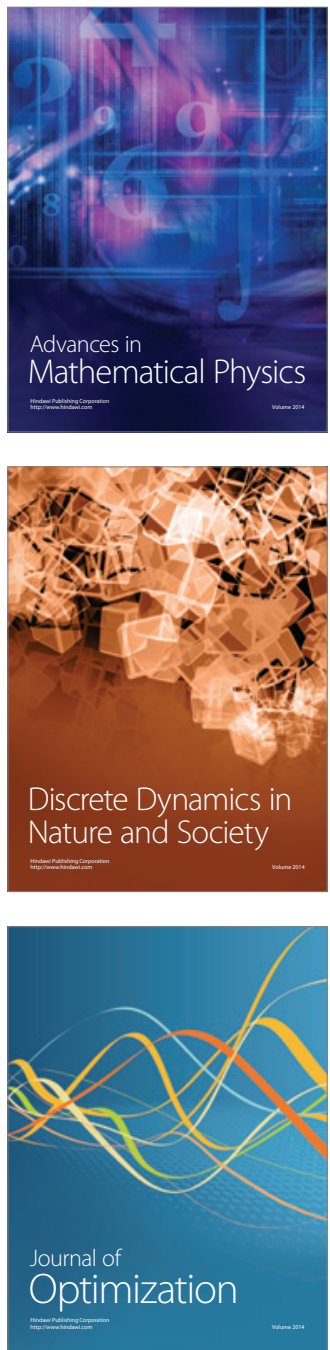